\section{Genotype-environment interaction}

\section{in schizophrenia-spectrum disorder}

\author{
Long-term follow-up study of Finnish adoptees \\ PEKK A TIENARI, LYMAN C. WYNNE, ANNELI SORRI, ILPO LAHTI, \\ KRISTIAN LÄKSY, JUHA MORING, MIKKO NAARALA, PENTTI NIEMINEN \\ and KARL-ERIK WAHLBERG
}

\begin{abstract}
Background Earlier adoption studies have convincingly confirmed the importance of a genetic contribution to schizophrenia. The designs, however, did not incorporate observations of the rearing-family environment.
\end{abstract}

\begin{abstract}
Aims To test the hypothesis that genetic factors moderate susceptibility to environmentally mediated risks associated with rearing-family functioning.
\end{abstract}

\begin{abstract}
Method A Finnish national sample of adopted-away offspring of mothers with schizophrenia-spectrum disorders was compared blindly with adoptees without this genetic risk. Adoptive rearing was assessed using family rating scales based upon extended family observations at initial assessment. Adoptees were independently re-diagnosed after a median interval of 12 years, with register follow-up after 21 years.
\end{abstract}

Results In adoptees at high genetic risk of schizophrenia, but not in those at low genetic risk, adoptive-family ratings were a significant predictor of schizophreniaspectrum disorders in adoptees at longterm follow-up.

\section{Conclusions Adoptees at high genetic risk are significantly more sensitive to adverse v. 'healthy' rearing patterns in adoptive families than are adoptees at low genetic risk.}

Declaration of interest None. Funding detailed in Acknowledgements.
In adoption studies genetic and rearing factors can be disentangled because the biological parents are not the rearing parents. Earlier adoption studies have confirmed convincingly the importance of a genetic contribution in schizophrenia. The designs, however, had not incorporated observations on the rearing-family environment. In this report from the Finnish Adoption Study, our aim is to clarify whether genetic risk for schizophrenia moderates the effects of adoptive rearing families. We have tried to extend earlier findings from adoption studies of schizophrenia (Rosenthal et al, 1971; Kety et al, 1994) by generating a larger sample of adoptees; obtaining standardised personal interviews with all subjects whenever possible, using DSM-III-R criteria (American Psychiatric Association, 1987); carrying out direct investigation of adoptive rearing families with home observations and interviews; and following up adoptees who were initially not at the age of risk for schizophrenia.

\section{Genotype-environment interaction}

To an important degree, genetic effects on behaviour arise because they either influence the extent to which the individual is likely to be exposed to individual differences in environmental risk or they affect the susceptibility of the individual to environmental adversities (Rutter et al, 2001). Genotype-environment interaction can be defined as genetic control of sensitivity to environmental factors, or environmental control of gene expression (Kendler \& Eaves, 1986). Thus, some genotypes are more likely than others to develop a disorder in the event of exposure to certain environmental factors. In genotypeenvironment interaction, the disorder will tend to cluster in families not because of a direct genetic effect, but because relatives are more vulnerable to the risk-increasing effect of a prevalent environmental risk factor (van Os \& Marcekis, 1998). A moderator (genotype) specifies on whom or under what conditions a mediator, such as rearing environment, will produce the outcome (Kraemer et al, 2001). Here, outcome is the presence or absence of a schizophrenia-spectrum disorder in the adoptee.

\section{METHOD}

A Finnish nationwide sample of adoptedaway offspring of mothers with diagnoses of schizophrenia-spectrum disorders was selected for blind comparison with adoptedaway offspring of biological mothers without schizophrenia-spectrum diagnoses. Matched on demographic variables, the adoptive parents of these samples at high $v$. low genetic risk were observed, interviewed and tested to evaluate independently the environments of the families.

\section{Sampling}

The full details of sample selection have been reported elsewhere (Tienari et al, 2000). In summary, hospital records were reviewed for all 19447 women in Finnish psychiatric hospitals on 1 January 1960 or admitted subsequently through to 1979 , identifying those who had been diagnosed at least once with schizophrenic or paranoid psychoses. This list was checked manually through every census and parish register in the country to find those index mothers who had adopted away one or more offspring. Their index offspring and their adoptive families were matched demographically with control adoptive families and offspring that had been adopted away by diagnostically unscreened biological control mothers.

\section{Biological mother diagnostic procedures}

Later, research diagnoses using DSM-III-R criteria were obtained through review of initial and subsequent hospital and clinic records and with personal research interviews carried out with all available index and control biological mothers and fathers (Tienari et al, 2000). The diagnosticians were blind to the status of the offspring who had been adopted away.

Additionally, for biological mothers and all other subjects in the study, Finnish national computerised registers were searched. Up to the end of November 
2000, a register giving reasons for death and, to 31 December 2001, the Hospital Discharge Register for all public and private in-patients were surveyed systematically. To October 1994, other register searches were carried out for diagnoses that justified disability pensions, gave information on sick leaves prescribed by a doctor, listed free medication prescribed for certain illnesses, including psychoses, and recorded information about criminality.

\section{Adoptive family assessments}

Adoptive families were investigated by experienced psychiatrists in their homes, directly and intensively, with tape-recorded procedures that usually took 2 days (14$16 \mathrm{~h})$. The clinical procedures included joint interviews with the whole family and with the parental couples, as well as semi-structured personal interviews with family members (Tienari et al, 1987). Total information from clinical observations and interviews, but not test data, was used to rate family functioning using a 33-item Finnish-language instrument the Oulun PerheArviointiSkaala (Oulu Family Rating Scale; OPAS) (Tienari et al, 1994). The OPAS had been developed for clinical evaluation of family relationships during interviews and observation in the family home. At the time of initial assessment, 378 adoptees had been born between 1926 and 1976 (11 adoptees born between 1977 and 1979 were not included). Of 378 families, 370 were contacted; only 25 refused and 345 were met personally; OPAS family ratings are available for 303 adoptees.

\section{Adoptee diagnostic procedures}

Of the 303 adoptees in families with OPAS ratings, 145 had biological mothers with a diagnosis of a schizophrenia-spectrum disorder. They have been defined as at high genetic risk. The 158 adoptees defined as at low genetic risk had biological mothers with a non-schizophrenia-spectrum psychiatric diagnosis or no psychiatric diagnosis. The median age of adoptees at the initial assessment was 23 years (inter-quartile range (IQR) 17-33; range 11-57 years). Beginning in 1977, semi-structured personal interviews were carried out with the adoptees. The interviewing psychiatrists of the adoptees and adoptive parents were kept blind as to the index/control status of the biological parents. Adoptees were reevaluated in a second wave that took place after a median interval of 12 years. New research psychiatrists were blind to all prior assessments of the adoptees and the biological and adoptive relatives. The follow-up interview schedules included an expanded lifetime version of the Present State Examination (PSE; Wing et al, 1974), the Structured Clinical Interview for Axis II Personality Disorders (SCID-II; Spitzer et $a l, 1989$ ) and the Structured Interview for Schizotypy (SIS; Kendler et al, 1989). Finally, the diagnostic status of the adoptees was rechecked at the end of register follow-up 21 years after initial assessment, when their median age was 44 years (IQR 38-52).

The principal, best-estimate, hierarchically most severe lifetime diagnoses were assigned on the basis of meeting DSM-III-R criteria for Axis I or Axis II psychiatric disorders based on all available data for all adoptees (personal interviews, keyinformant interviews and register survey and medical record reviews). Diagnoses were made at three levels of certainty: definite; probable; and possible. The focus in this report is on adoptees with diagnoses at definite and probable certainty levels. As described previously (Tienari et al, 2000), three stringent approaches for assessing and maintaining interrater diagnostic reliability were carried out, including checks on rater drift over time.

For purposes of the present report, we focus upon adoptees with DSM-III-R diagnoses of schizophrenia and ten other disorders that have been considered genetically linked to schizophrenia by one or more previous researchers. These constitute what we call the putative 'broad' schizophrenia spectrum (Tienari et al, 2003).

Of the 303 adoptees in this report, their lifetime diagnoses were as follows: schizophrenia, 14 (4.6\%; high genetic risk/low genetic risk 11/3); other non-affective psychotic disorders, $3(1.0 \%$; high genetic risk/low genetic risk 3/0), specifically, schizophreniform disorder (1) and delusional disorder (2); affective psychoses, i.e. bipolar and depressive disorders with psychotic features, $5(1.7 \%$; high genetic risk/low genetic risk 4/1); and cluster A personality disorders, 18 (5.9\%; high genetic risk/low genetic risk 14/4), namely, schizotypal $(5 / 0)$, schizoid (5/1), and paranoid (1/1) personality disorders, plus avoidant $(4 / 2)$ personality disorder. The $40 \quad(13.2 \%)$ adoptees in the broad schizophrenia spectrum were divided into 32 at high genetic risk $(10.6 \%)$ and 8 at low genetic risk (2.6\%).
A total of $19(6.3 \%)$ of these 40 adoptees had a schizophrenia-spectrum diagnosis at the initial assessment (schizophrenia, 7; schizo-affective disorder, 1 (final diagnosis of schizophrenia); schizophreniform disorder, 2 (one of these had final diagnosis of schizophrenia); delusional disorder, 3 (one had final diagnosis of schizophrenia); bipolar psychosis, 1; schizotypal personality disorder, 3; and schizoid personality disorder, 2). All of these 19 adoptees were in the high-geneticrisk group.

\section{Construction of the OPAS scales}

Initially, a review of existing family rating scales was carried out to identify those that could be used with a wide range of families observed directly in their homes and those that would fit with the special goals and conditions of the study as outlined above. A major source of scales was the BeaversTimberlawn Family Evaluation Scale (Lewis et al, 1976). Also, scales were specially constructed to tap major concepts thought to be relevant for families with offspring with schizophrenia. After much discussion and a pilot trial of possible scales, the team of investigators selected 33 sub-scales, creating what was called the OPAS (Oulun PerheArviointiSkaala, Oulu Family Rating Scale).

Each sub-scale could be rated at five levels from 'healthy' to 'severely dysfunctional'. An effort was made to specify not only the content of each scale thematically but also to define operationally, insofar as possible, what behaviours and relationships would apply at levels 1, 3 and 5, with levels 2 and 4 left for intermediate ratings (the full manual is available from the authors). The interviews were recorded on audiotape in order to have material for interrater reliability studies and for later review both by the interviewer and other investigators pursuing various specific hypotheses.

Optimal grouping of the OPAS subscales was a complicated task. A series of statistical analyses were carried out, especially using factor and cluster analyses. Several criteria evolved for deciding that six sub-scales were unsuitable for systematic study, because of low reliability using Cronbach's alpha coefficient, or poor interrater reliability, or many missing values, or because they had such a narrow range of variability in the ratings that their predictor value would be negligible. There were also missing scores on some sub-scales in 94 
families. For each of these ratings, a score was substituted from the family with the most similar arithmetic mean for all OPAS categories ('nearest neighbour method'; Chen \& Shao, 2001). Imputed scores were used for grouping of scales only. Explanatory factor analysis was then performed using the 27 remaining OPAS sub-scales with imputed scores. The extraction method was principal component analysis with equamax rotation. Equamax rotation was used to balance the need for interpretable factors with the need for simplified, interpretable variables. In this analysis three factors were extracted. The content of the resulting three factors (dimensions) can be labelled as 'critical/conflictual' (11 subscales), 'constricted' (8 sub-scales), and 'boundary problems' (5 sub-scales). Three more scales were excluded on the basis of low factor loadings. The loadings and final groupings of the surviving 24 sub-scales are presented in Table 1 (together with the intraclass correlations of interrater reliability). Factor 1 'critical/conflictual' seemed to include features similar to those rated as expressed emotion (Leff \& Vaughn, 1985) and as communication deviance (Wahlberg et al, 1997).

For each adoptive family, arithmetic means of the raw scores (i.e. original ratings given by interviewing psychiatrists) were calculated for each of the three domains. No imputed scores were used here. These mean scores were dichotomised at the median for analyses of each domain. The purpose of collapsing continuous explanatory variables into dichotomous ones was to clarify the relationship between outcome and (environmental and genetic) risk factors. Initial analyses were carried out on the basis of $2 \times 2$ tables calculating $P$-values from $\chi^{2}$ or Fisher's exact test.

Statistical significance of the risk difference (attributable risk) between high- and low-genetic-risk adoptees that is due to dysfunction in the adoptive family (interaction on additive scale; Darroch, 1977) was evaluated using Wald's test (Armitage et al, 2002; van Os et al, 2003).

Logistic regression was employed to estimate odds ratios and to adjust the potential effect of adoptee's gender, age at the end of follow-up and age at final placement to adoptive family. Some studies have found gender variation in schizophrenia; age at placement is relevant to variations

Table I Reliability coefficients and results of factor analysis for 24 sub-scales of the Oulu Family Rating Scale (OPAS) scales

\begin{tabular}{|c|c|c|c|c|}
\hline \multirow[t]{2}{*}{ OPAS sub-scales } & \multirow[t]{2}{*}{ Interrater reliability coefficient' } & \multicolumn{3}{|c|}{ Factor loadings } \\
\hline & & ‘Critical/conflictual’ & 'Constricted’ & 'Boundary problems' \\
\hline Criticism & 0.72 & 0.793 & & \\
\hline Affect, intense, explosive & 0.65 & 0.747 & & \\
\hline Conflict, parent-parent & 0.65 & 0.710 & & \\
\hline Non-acknowledgement & 0.63 & 0.677 & & \\
\hline Insecurity in the family & 0.50 & 0.647 & & \\
\hline Lack of empathy & 0.68 & 0.616 & & \\
\hline Dissatisfaction with family & 0.70 & 0.612 & & \\
\hline Conflict, parent-offspring & 0.77 & 0.608 & & \\
\hline Communication, disrupted & 0.66 & 0.604 & & \\
\hline Inflexibility & 0.58 & 0.594 & & \\
\hline Anxiety, manifest & 0.70 & 0.546 & & \\
\hline Affect, flat & 0.68 & & 0.824 & \\
\hline Narrow range of effect & 0.49 & & 0.803 & \\
\hline Communication, constricted & 0.69 & & 0.744 & \\
\hline Incongruence between interviewer/family & 0.67 & & 0.624 & \\
\hline Lack of humour & 0.55 & & 0.591 & \\
\hline Suspicious of extrafamilial context & 0.61 & & 0.589 & \\
\hline Passivity, apathy, anergy & 0.50 & & 0.574 & \\
\hline Hierarchy, rigid structure & 0.63 & & 0.555 & \\
\hline Hierarchy, chaotic structure & 0.53 & & & 0.805 \\
\hline Individual enmeshment & 0.56 & & & 0.752 \\
\hline Generational enmeshment & 0.34 & & & 0.708 \\
\hline Communication, amorphous & 0.53 & & & 0.640 \\
\hline Inadequate daily problem-solving & 0.49 & & & 0.530 \\
\hline Reliability coefficients, mean (range) & & $0.65(0.50-0.77)$ & $0.60(0.49-0.69)$ & $0.49(0.34-0.56)$ \\
\hline
\end{tabular}

I. Blind ratings from audiotaped family interviews by four interviewing psychiatrists. 
Table 2 Frequency and percentage distributions of diagnoses of schizophrenia-spectrum disorders at long-term follow-up in high-genetic-risk and low-genetic-risk adoptees for three adoptive-family domains

\begin{tabular}{|c|c|c|c|c|c|c|c|c|}
\hline \multirow[t]{2}{*}{ Dimension of adoptive family } & \multicolumn{4}{|c|}{ High-genetic-risk adoptees } & \multicolumn{4}{|c|}{ Low-genetic-risk adoptees } \\
\hline & $\begin{array}{c}\text { Non-spectrum } \\
n(\%)\end{array}$ & $\begin{array}{c}\text { Spectrum } \\
n(\%)\end{array}$ & $\begin{array}{c}\text { Total } \\
n\end{array}$ & $P$ & $\begin{array}{c}\text { Non-spectrum } \\
n(\%)\end{array}$ & $\begin{array}{l}\text { Spectrum } \\
\text { n (\%) }\end{array}$ & $\begin{array}{c}\text { Total } \\
n\end{array}$ & $P$ \\
\hline \multicolumn{9}{|l|}{ 'Critical/conflictual' } \\
\hline Low OPAS ratings' & $61(92.4)$ & $5(7.6)$ & 66 & & $83(96.5)$ & $3(3.5)$ & 86 & \\
\hline \multirow[t]{2}{*}{ High OPAS ratings ${ }^{2}$} & $52(65.8)$ & $27(34.2)$ & 79 & & $67(93.1)$ & $5(6.9)$ & 72 & \\
\hline & & & & $P<0.001$ & & & & $P=0.470$ \\
\hline \multicolumn{9}{|l|}{ 'Constricted' } \\
\hline Low OPAS ratings & $73(93.6)$ & $5(6.4)$ & 78 & & $97(98.0)$ & $2(2.0)$ & 99 & \\
\hline \multirow[t]{2}{*}{ High OPAS ratings } & $40(59.7)$ & $27(40.3)$ & 67 & & $52(89.7)$ & $6(10.3)$ & 58 & \\
\hline & & & & $P<0.001$ & & & & $P=0.052$ \\
\hline \multicolumn{9}{|l|}{ Boundary' problems } \\
\hline Low OPAS ratings & $53(89.8)$ & $6(10.2)$ & 59 & & 91 (95.8) & $4(4.2)$ & 95 & \\
\hline \multirow[t]{2}{*}{ High OPAS ratings } & $60(69.8)$ & $26(30.2)$ & 86 & & $59(93.7)$ & $4(6.3)$ & 63 & \\
\hline & & & & $P=0.004$ & & & & $P=0.714$ \\
\hline \multicolumn{9}{|l|}{ Mean score of three dimensions ${ }^{3}$} \\
\hline Low OPAS ratings & $65(94.2)$ & $4(5.8)$ & 69 & & $79(95.2)$ & $4(4.8)$ & 83 & \\
\hline \multirow[t]{2}{*}{ High OPAS ratings } & $48(63.2)$ & $28(36.8)$ & 76 & & $71(94.7)$ & $4(5.3)$ & 75 & \\
\hline & & & & $P<0.001$ & & & & $P=0.582$ \\
\hline \multicolumn{9}{|l|}{ Mean score of three dimensions ${ }^{4}$} \\
\hline Low OPAS ratings & $65(95.6)$ & $3(4.4)$ & 68 & & $79(95.2)$ & $4(4.8)$ & 83 & \\
\hline \multirow[t]{2}{*}{ High OPAS ratings } & $48(81.4)$ & II (I8.6) & 59 & & 71 (95.9) & $3(4.1)$ & 74 & \\
\hline & & & & $P=0.020$ & & & & $P=0.595$ \\
\hline
\end{tabular}

Non-spectrum, no diagnosis of schizophrenia-spectrum disorder; spectrum, diagnosis of schizophrenia-spectrum disorder.

I. Low OPAS ratings: ratings below the median (relatively healthy) for 24 sub-scales of the Oulu Family Rating Scale.

2. High OPAS ratings: above the median (relatively dysfunctional) for 24 sub-scales of the Oulu Family Rating Scale.

3. All families $(n=303)$.

4. Adoptees with diagnosis of schizophrenia-spectrum disorder at initial assessment excluded $(n=284)$.

$P$-values of Fisher's exact test (two-tailed).

in the environment at differing ages of placement, and age at follow-up is important in identifying late-onset schizophreniaspectrum disorder.

Estimation of odds ratio and its confidence intervals for environmental factors depends on the genetic risk interacting with the environmental variable. We have used the formula (described in Kleinbaum et al, 1982; Hosmer \& Lemeshow, 1989) for estimating odds ratios in the presence of interaction.

Differences of proportions of disordered adoptive families in the high-genetic-risk and low-genetic-risk groups of adoptees were calculated to assess possible effects of high $v$. low genetic risk on adoptive family functioning. We also report $95 \%$ confidence intervals of the adoptive family differences and evaluate statistical significance using the chi-squared test.

\section{RESULTS}

In Table 2 the distribution of schizophrenia-spectrum diagnoses in the adoptees is presented for the dichotomised family domains separated into high- and lowgenetic-risk adoptee groups. In the highgenetic-risk group there is a significant association $(P<0.001$ Fisher's exact test $)$ between disordered rearing and adoptee diagnosis of schizophrenia-spectrum disorder. This is not seen in the low-genetic-risk group. When all three dimensions were combined into one environmental variable, this summary variable (Table 2 ) shows the same pattern as found for each of the three domains.

Only in the high-genetic-risk adoptees was there a significant association between adoptee diagnosis of schizophrenia-spectrum disorder and rearing. This can be interpreted as an example of genotype-environment interaction, that is adoptees at genetic risk are more sensitive to problems in the adoptive family. Wald's test confirms the statistical significance of these additive statistical interactions (for the 'critical/conflictual' $\chi^{2}=8.915$, d.f. $=1, P=0.003$; for the 'constricted' $\chi^{2}=9.680$, d.f. $=1 ; P=0.002$; for the 'boundary problems' $\chi^{2}=5.196$, d.f. $=1, P=0.023$; and for mean score $\chi^{2}=15.604$, d.f. $\left.=1, P<0.001\right)$. If the 19 adoptees with diagnoses of schizophreniaspectrum disorder at initial assessment were excluded, there was still a statistically significant association between disordered rearing and adoptee diagnosis at the end of follow-up (Table 2). The exclusion was carried out to check whether adoptees with diagnoses of schizophrenia-spectrum disorder who were vulnerable had had a measurable diagnostic impact on the adoptive family before the initial assessment. 
Table 3 Prediction of schizophrenia-spectrum disorder in adoptees from genetic risk and assessment of family functioning (measured on the Oulu Family Rating Scale; OPAS) ( $n=303)$ using logistic regression analysis

\begin{tabular}{|c|c|c|c|c|c|}
\hline Variable & Regression coefficient & s.e. & $P$ of likelihood ratio test & Odds ratio & $95 \% \mathrm{Cl}$ \\
\hline \multicolumn{6}{|c|}{ (A) Main effects of $G$ and $E$} \\
\hline Environmental factor ${ }^{2}$ & 1.63 & 0.43 & 0.0001 & 5.10 & $2.20-11.80$ \\
\hline Gender & 0.24 & 0.37 & 0.50 & 1.28 & $0.62-2.63$ \\
\hline Age & -0.055 & 0.37 & 0.82 & 0.95 & $0.46-1.95$ \\
\hline Age at placement & 0.277 & 0.37 & 0.43 & 1.33 & $0.64-2.75$ \\
\hline \multicolumn{6}{|c|}{ (B) $\mathbf{G} \times \mathbf{E}$ interaction added } \\
\hline Genetic factor ${ }^{\prime}$ & 0.164 & 0.73 & 0.82 & & \\
\hline Environmental factor ${ }^{2}$ & 0.11 & 0.73 & 0.88 & & \\
\hline $\mathrm{G} \times \mathrm{E}$ interaction ${ }^{3}$ & 2.20 & 0.92 & 0.018 & & \\
\hline
\end{tabular}

G, genotype; E, environment.

I. Any mental disorder of the biological mothers (schizophrenia-spectrum disorders, $n=145$; non-schizophrenia-spectrum or no disorders, $n=158$ ).

2. Family functioning in adoptive rearing family. Total score $=$ mean score of three OPAS groups.

3. Estimation of odds ratio depends on the environmental factor interacting with genetic vulnerability. Odds ratio is adjusted for age at end of follow-up (or of death) and gender of adoptees and for age of adoptee at the time of final placement in the adoptive family.

In Table 3 the logistic regression model without interaction is presented. Both genotype and environment have statistically significant main effects. However, when the genotype-environment interaction term is added, the model improves $(P=0.018$ using $\log$ likelihood ratio test). The odds ratio also improves substantially. Thus, to assess correctly the risk of environment for adoptee disorder, we must include the interaction of environment with genotype because the odds ratio is not constant over genotype. In the presence of interaction between genotype and environment, the adjusted odds ratio for environment is 1.11 (95\% CI $0.37-3.39$ ) in the low-genetic-risk group but 10.0 (95\% CI $3.26-30.69$ ) in the high-genetic-risk group.

If adoptees with a diagnosis of schizophrenia-spectrum disorder at initial assessment $(n=19)$ are excluded, the adjusted odds ratio for environment in the presence of interaction between genotype and environment is lower but still significant $(5.48 ; 95 \%$ CI $1.42-21.08)$ in the high-genetic-risk group for adoptees who initially had a non-schizophrenia-spectrum psychiatric diagnosis or no diagnosis. The family OPAS evaluation (mean total score of three dimensions) does not differ between the high- and low-genetic-risk groups $\left(P=0.390 ; \chi^{2}\right.$ test). In Table 4 'boundary problems' in adoptive family is the only domain in which there is a statistically significant difference between the highand low-genetic-risk groups. This exception suggests differentiation among adoptive family domains but is not supported by other evidence.

\section{DISCUSSION}

\section{Main findings}

The results demonstrate that adoptees at high genetic risk for schizophrenia are more sensitive to problems in the rearing adoptive family, both in the three domains (factor groups) measuring adoptive rearing ('critical/conflictual', 'constricted' and 'boundary problems') and in the total score for the three domains. An alternative way to view the findings is that there appears to be a protective effect in having been reared in a 'healthy' adoptive family, i.e. with a low OPAS rating. High-genetic-risk adoptees reared in families with low OPAS ratings (both in each OPAS domain and in the three-dimension mean) had significantly fewer schizophrenia-spectrum outcomes

Table 4 Proportions (\%) of disordered adoptive families in high-genetic-risk and low-genetic-risk groups

\begin{tabular}{|c|c|c|c|c|c|}
\hline Dimension of adoptive family from OPAS ratings & $\begin{array}{c}\text { Proportion of disordered } \\
\text { families in high-risk } \\
\text { groups }\end{array}$ & $\begin{array}{l}\text { Proportion of disordered } \\
\text { families in low-risk } \\
\text { groups }\end{array}$ & $\begin{array}{l}\text { Difference } \\
\text { proportions }\end{array}$ & $95 \% \mathrm{Cl}$ & $\begin{array}{c}P \text { of } \\
\text { the } \chi^{2} \text { test }\end{array}$ \\
\hline 'Critical/conflictual' adoptive family & 54.5 & 45.6 & 9.257 & -1.96 to 20.48 & 0.121 \\
\hline 'Constricted' adoptive family & 46.2 & 36.9 & 9.264 & -1.82 to 20.35 & 0.102 \\
\hline 'Boundary problems' in adoptive family & 59.3 & 39.9 & 19.437 & 8.38 to 30.49 & 0.001 \\
\hline Mean score of three dimensions of adoptive family' & 52.4 & 47.5 & 4.94 & -6.31 to 16.30 & 0.390 \\
\hline Mean score of three dimensions of adoptive family ${ }^{2}$ & 46.6 & 47.1 & 1.567 & -10.09 to 13.23 & 0.909 \\
\hline
\end{tabular}

OPAS, Oulu Family Rating Scale.

I. All families $(n=303)$.

2. Adoptees with diagnosis of schizophrenia-spectrum disorder at initial assessment excluded $(n=284) ; n$ values taken from Table 2 . 
than high-genetic-risk adoptees reared in families with high OPAS ratings ( $P$-values vary from $<0.001$ to 0.004$)$. A similar finding was reported in our earlier report using factor scores instead of raw scores from the Finnish Study. Also in the same report the age-corrected morbid risk for schizophrenia in high-genetic-risk adoptees reared in 'healthy' families was $1.49 \%$ but $13.04 \%$ for high-genetic-risk adoptees reared in 'dysfunctional' families, i.e. with both genetic risk and environmental risk present (Tienari et al, 2002).

We have found that the joint effect of high genetic risk and a dysfunctional rearingfamily environment is essentially equal for each of the three groups of OPAS scales that have been differentiated by factor analysis. This finding suggests that there is no specific, sharply delimited form of environmental problem and that the biological and psychosocial environment has multiple components, perhaps like multifactorial genetics.

\section{Biological environment}

We have focused upon the aspects of the rearing-family environment in this report, but we assume that the relevant environment that facilitates gene expression for schizophrenia-spectrum disorders very likely includes complementary and developmental aspects of the biological environment from the foetal stage onward (Weinberger, 1987).

\section{Genotype-environment interaction}

In the light of the relatively neglected consideration of the psychosocial environment by most researchers into schizophrenia, we believe that our finding is striking that neither high genetic risk nor dysfunctional family environment alone predicts adoptee illness. This can be interpreted as meaning that genetic risk and the rearing environment have an interactive effect, both in promoting the emergence of illness and protecting against such an outcome.

Conceptually, the findings support the hypothesis of significant genotypeenvironment interaction as defined by Kendler \& Eaves (1986), i.e. genetic control of sensitivity to the environment or environmental control of genetic expression. In other words, a moderator (genotype) specifies for whom or under what conditions rearing environment is associated with the outcome (schizophrenia-spectrum disorder in adoptees). These results are also in accord with the hypothesis of Gottesman \& Bertelsen (1989), that discordance in identical twins could be explained primarily by the capacity of schizophrenic genotype or diathesis to be unexpressed unless it is released by some kind of environmental, including non-familial, stressors.

\section{Stress-diathesis model and genotype-environment correlations}

Our results support the popular stressdiathesis model of the aetiology of psychopathology. In this model, environmental stressors are hypothesised to have a particularly deleterious effect only on those individuals with a genetic diathesis or predisposition to a particular psychopathology (Plomin et al, 2000). Theoretically, one can hypothesise the possibility of evocative genotype-environment correlation if the children's genetically influenced characteristics play a role in shaping their environments. One would then expect that adoptive families with an adoptee at a high genetic risk would differ from those with adoptees at low risk.

\section{Direction of effects}

With a dichotomised outcome, it is not possible to evaluate the possibility that the relationship of these variables is nonlinear, although possibly significant. Reciprocal, bidirectional effects between rearing parents and their children almost certainly do take place. However, these reciprocal effects cannot be separated measurably without intensive developmental study. It is possible that adoptive families with an adoptee at high genetic risk might differ from those with an adoptee at low genetic risk - what might be called 'reverse causality'. Another possibility is that such an effect could be found in relation to a more specific form of adoptive-family functioning. For example, this could take place in the 'critical/conflictual' domain, where family functioning might include features such as expressed emotion (Leff \& Vaughn, 1985). However, high $v$. low genetic risk of the adoptees does not generate such differences between 'healthy' and 'dysfunctional' families, at least when assessed with the OPAS ratings of adoptive families. This result with OPAS ratings is consistent with our earlier finding that there was no difference in the communication deviance of the adoptive parents of the high- and lowgenetic-risk adoptee groups (Wahlberg et al, 1997). These results indicate that the adoptees at high genetic risk did not have a special measurable impact that produced increased communication deviance in the rearing parents or that generated other observable problems in the adoptive families.

Goldstein (1987) found that communication deviance in the parents of troubled adolescents predicts schizophreniaspectrum diagnosis in children 15 years later. The Finnish adoption study (details available from the authors upon request) found that in adoptees without a psychiatric diagnosis at initial assessment, communication deviance in adoptive parents predicted adoptee diagnosis at 19-year follow-up. When high genetic risk is combined with rearing by parents with high communication deviance, the risk for a psychiatric diagnosis is increased significantly compared with low genetic risk combined with rearing by parents with low communication deviance. Johnson et al (2001) showed that, in a large population cohort interviewed repeatedly, disordered parenting was a more important predictor of the child's psychiatric diagnosis than was parental psychiatric diagnosis.

In summary, we have shown that disordered adoptive rearing assessed in the adoptive families of adoptees without schizophrenia-spectrum disorders predicted schizophrenia-spectrum disorders at 21year follow-up. However, only in the adoptees at high genetic risk was there a significant association between the measure of adoptive family functioning and adoptee schizophrenia-spectrum diagnosis. The same result was found when a subgroup of adoptees with schizophrenia-spectrum diagnoses at initial assessment was excluded. This indicates, in our view, that adoptees at high genetic risk are more sensitive to adverse (or protective) environmental effects in an adoptive rearing environment than are adoptees at low genetic risk. This adoption study of schizophrenia-spectrum disorder supports the hypothesis of interaction of genotype and environment. The presumed genotype appears to be 'sensitive' not only to dysfunction in the family environment but also to protective environmental factors.

\section{ACKNOWLEDGEMENTS}

Partial funding by grant MH 39663 from the National Institute of Mental Health, the Scottish Rite Schizophrenia Research Programme, the National 
Research Board in Finland and the Signe och Ane Gyllenberg Foundation.

\section{REFERENCES}

American Psychiatric Association (1987) Diagnostic and Statistical Manual of Mental Disorders (3rd edn, revised) (DSM-III-R). Washington, DC: APA

\section{Armitage, P., Berry, G. \& Matthews, J. N. S. (2002)}

Statistical Methods in Medical Research (4th edn).

Oxford: Blackwell Science.

Chen, J. \& Shao, J. (200I) Jackknife variance estimation for nearest-neighbor imputation. Journal of the American Statistical Association, 96, 260-269.

Darroch, J. (1997) Biological synergism and parallelism American Journal of Epidemiology, 145, 66I-668.

Goldstein, M. J. (1987) Family interaction patterns that antedate the onset of schizophrenia and related disorders: a further analysis of data from a longitudinal, prospective study. In Understanding Major Mental Disorder: The Contribution of Family Interaction Research (eds K. Hahlweg \& M. J. Goldstein), pp. II-32. New York: Family Process Press.

Gottesman, I. I. \& Bertelsen, A. (1989) Confirming unexpressed genotypes for schizophrenia. Risks in the offspring of Fischer's Danish identical and fraternal discordant twins. Archives of General Psychiatry, 46 867-872.

Hosmer, D.W. \& Lemeshow, S. (1989) Applied Logistic Regression. New York: John Wiley \& Sons.

Johnson, J. G., Cohen, P., Kasen, S., et al (200I) Association of maladaptative parental behavior with psychiatric disorder among parents and their offspring. Archives of General Psychiatry, 58, 453-460.

Kendler, K. S. \& Eaves, L. J. (1986) Models for the joint effect of genotype and environment on liability to psychiatric illness. American Journal of Psychiatry, 143, 279-289.

Kendler, K. S., Lieberman, J. A. \& Walsh, D. (1989) The Structured Interview for Schizotypy (SIS). A preliminary report. Schizophrenia Bulletin, I5, 559-57I.

Kety, S. S., Wender, P. H., Jacobsen, B., et al (1994) Mental illness in the biological and adoptive relatives of schizophrenic adoptees. Replication of the Copenhagen study in the rest of Denmark. Archives of General Psychiatry, 5I, 442-455.

Kleinbaum, D. G., Kupper, L. L. \& Morgenstern, H (1982) Epidemiologic Research - Principles and Quantitative Methods. New York: Van Nostrand Reinhold.

Kraemer, H. C., Stice, E., Kazdin, A., et al (200I) How do risk factors work together? Mediators, moderators and independent, overlapping, and proxy risk factors. American Journal of Psychiatry, I58, 848-856.

Leff, J. P. \& Vaughn, C. (1985) Expressed Emotion in Families. New York: Guilford Press.

Lewis, J. M., Beavers, W. R., Gosset, J.T., et al (1976) No Single Thread. Psychological Health in Family Systems. New York: Brunner/Mazel.

Plomin, R., DeFries, J. C., McClearn, G. E., et al (2000) Behavior Genetics (4th edn). New York: W. H. Freeman.

Rosenthal, D., Wender, P. H., Kety, S. S., et al (197I)

The adopted-away offspring of schizophrenics. American Journal of Psychiatry, 128, 307-31I.

\section{CLINICAL IMPLICATIONS}

- The assessment of family functioning could help to understand gene expression in the clinical outcomes of schizophrenia spectrum disorders.

- The joint effects (interaction) of genetic risk and family functioning predict clinical outcomes of schizophrenia spectrum disorders, or relative health, more significantly than does either the genetic variable or the environmental variable when evaluated separately. Clinically, both realms deserve careful attention.

- A wide, multi-factorial range of forms of genetic risk and family dysfunction all might contribute to the clinical manifestations of schizophrenia spectrum disorders.

\section{LIMITATIONS}

- Childhood and early adolescent development were not assessed directly in this report.

- Assessment of family functioning at a given point in time, even with prolonged observation, might not tap crucial developmental changes.

- Reciprocal, not unidirectional effects, within family relationships make impossible and inappropriate interpretations about simple, unidirectional 'causality' assigned to adoptive parents or to the adoptees.

PEKKA TIENARI, MD, Department of Psychiatry, University of Oulu, Finland; LYMAN C.WYNNE, MD, PhD, University of Rochester, USA; ANNELI SORRI, MD, ILPO LAHTI, MD, KRISTIAN LÄKSY, MD, JUHA MORING, MD, MIKKO NAARALA, MD, PENTTI NIEMINEN, PhD, KARL-ERIK WAHLBERG, PhD, Department of Psychiatry, University of Oulu, Finland

Correspondence: Professor Pekka Tienari, Department of Psychiatry, University of Oulu, PL 5000, 90014 Oulun yliopisto, Finland. Tel: +358(0)50 35। 7927; fax: +358(0)8 333 167; e-mail ptienari@cc.oulu.fi

(First received 26 June 2003, final revision 6 October 2003, accepted 3 November 2003)

Rutter, M., Pickles, A., Murray, R. M., et al (200I) Testing hypotheses on specific environmental causal effects on behavior. Psychological Bulletin, 127, 291-324.

Spitzer, R. L., Williams, J. B.W. \& Gibbon, M. (1989) Structured Clinical Interview for DSM-III-R Personality Disorders. SCID-2 (9/1/89 Version). New York: Biometric Research Department, New York State Psychiatric Institute.

Tienari, P., Lahti, I., Sorri, A., et al (1987) The Finnish adoptive family study of schizophrenia: possible joint effects of genetic vulnerability and family interactions. In Understanding Major Mental Disorder: the Contributions of Family Interaction Research (eds K. Hahlweg \& M. J. Goldstein), pp. 33-54. New York: Family Process Press.

Tienari, P., Wynne, L. C., Moring, J., et al (1994) The Finnish Adoptive Family Study of Schizophrenia: implications for family research. British Journal of Psychiatry, 164 (suppl. 23), 20-26.

Tienari, P., Wynne, L. C., Moring, J., et al (2000) Finnish adoptive family study: sample selection and adoptee DSM-III-R diagnoses. Acta Psychiatrica Scandinavica, I0I, 433-443.

Tienari, P., Wynne, L. C., Sorri, A., et al (2002) Genotype-environment interaction in the Finnish adoptive family study - interplay between genes and environment? In Risk and Protective Factors in Schizophrenia (ed. H. Häfner), pp. 29-38. Darmstadt: Springer Verlag.

Tienari, P., Wynne, L. C., Läksy, K., et al (2003) Genetic boundaries of the schizophrenia spectrum: Evidence from the Finnish adoptive family study. American Journal of Psychiatry, 160, 1587-1594.

van Os, J. \& Marcekis, M. (1998) The ecogenetics of schizophrenia. Schizophrenia Research, 32, 127-135.

van Os, J., Hanssen, M. A., Bak, M., et al (2003) Do urbanicity and familial liability coparticipate in causing psychosis? American Journal of Psychiatry, 160, 477-482.

Wahlberg, K. E., Wynne, L. C., Oja, H., et al (1997) Gene-environment interaction in vulnerability to schizophrenia: findings from the Finnish Adoptive Family Study of Schizophrenia. American Journal of Psychiatry, I54, 355-362.

Weinberger, D. R. (1987) Implications of normal brain development for the pathogenesis of schizophrenia. Archives of General Psychiatry, 44, 660-669.

Wing, J. K., Cooper, J. E. \& Sartorius, N. (1974) Measurement and Classification of Psychiatric Symptoms: An Instruction Manual for the PSE and Catego Program. London: Cambridge University Press. 